\title{
Darussyifa: The Islamic Charitable and Medicinal Society Building (Malay Version)
}

\author{
Uqbah Iqbal* \\ Life Planner, Malaysia
}

*Corresponding author: Uqbah Iqbal, Life Planner, Suite P4, Level 31, AIA Cap Square Tower, Jalan Munshi Abdullah, 50100 Golden Triangle, Kuala Lumpur, Malaysia.

Received Date: October 12, 2018

Published Date: October 17, 2018

\section{Opinion}

Written by Dr. Amran Kasimin, to engage in traditional Malay treatments, whether called a handler or a shaman, the following process must be passed. One may be involved with traditional treatment solely because of one of his offspring, i.e., whether his grandfather or grandmother consists of a handler or a shaman. Usually the decrease occurs, after the deceased person dies. Decrease in the knowledge can occur in unnoticed ways. However, in practice the person who received the knowledge may have these signs. Decreases may also occur directly, or indirectly. It is said that live happily is when his grandparent or one of his parents intentionally reduces his knowledge and is consciously acknowledged by the person concerned. Declining knowledge may also occur by giving the property of the heirs to certain people of his family. In such a case, the gift of the object is only a symbol of the decline in the knowledge. Decline does not necessarily occur from a mother to her child, but it is also possible from a grandfather to one of his grandchildren or grandchildren.

In the Malay community, this decline is named after. Sometimes it can be used for treatment, and sometimes it does not. In essence involving fine beings. There has never been a family who keeps the dagger without the headship received from his grandfather experiencing some odd events. According to the respondent, that is the case after his grandfather died. The dagger he kept was used to kill people. That is among the early signs of a context between people and certain things. People who do not want to be accompanied may be disturbed by these subtle creatures. There are also people who engage in traditional treatments solely based on knowledge acquired through mere inheritance. In addition, there are also those who study with certain people. They learn whether the knowledge involved the use of various spells of martial and profanity or the verses of the Koran and prayers, or both. There are also people who seek knowledge of traditional treatment by engaging with subtle creatures i.e., whether to study certain rules to call subtle creatures whether to be made valid, to be defended or to be made brothers. The process of engaging with subtle creatures can occur through the process of descent as described above. Indeed, there are subtle creatures that lie down with humans that can be used for treatment purposes without demanding.

Treatment knowledge can be learned by means of learning involving the verses of the Quran, the hadiths, the prayers or the spells that are not contrary to the teachings of Islam. The second is to learn the treatment of medicine that uses the spell of martial and profane or both of which are Islamic treatments and methods that are contrary to Islam. Traditionally, those who engage in Islamic treatment are not known as handlers or shamans. There are also those who engage in these traditional treatments with just a dream, which is a dream to meet certain people who teach certain spells to practice. This method is better known as the learning method through inspiration. Not least are those who study the sciences first in the way of learning. At bedtime, he dreams of being approached by certain people and taught him medical knowledge, including the use of the verses of the Koran and prayers. There are also people who get treatment by uses certain prayers from the sound he hears when he is conscious or asleep. The knowledge is known as Ladunni Science, a gift from God s.w.t. to certain people only. Decreasing is one of the ways of treatment that is also done in the Malay community. The method has a direct relationship with the object that is considered to be the spirit, the supernatural powers that consist of jinn, elves, grandparents and others. 